\title{
Toward a Synergistic Version of Solution-Focused Brief Therapy: Enhanced Efficacy through the Body and Emotion
}

\author{
Jeffrey N. Lubin'1, Stephan Hendrick ${ }^{2}$, Branden Thornhill-Miller ${ }^{3,4}$, Todd I. Lubart ${ }^{5}$ \\ ${ }^{1}$ Department of Systemic and Psychodynamic Clinical Psychology, Université de Mons, Mons, Belgium \\ ${ }^{2}$ Faculty of Psychology and Educational Sciences, Department of Systemic and Psychodynamic Clinical Psychology, \\ Université de Mons, Mons, Belgium \\ ${ }^{3}$ Creativity Profiling Project, Paris Descartes University, Boulogne-Billancourt, France, \\ ${ }^{4}$ Philosophy Faculty, University of Oxford, Oxford, UK \\ ${ }^{5}$ Faculty of Psychology, Paris Descartes University, Boulogne-Billancourt, France \\ Email: jefnetan@gmail.com, HENDRICK@umons.ac.be, branden.miller@psy.ox.ac.uk, thornhill-miller@post.harvard.edu, \\ todd.lubart@parisdescartes.fr
}

How to cite this paper: Lubin, J.N., Hendrick, S., Thornhill-Miller, B. and Lubart, T.I. (2019) Toward a Synergistic Version of Solution-Focused Brief Therapy: Enhanced Efficacy through the Body and Emotion. Health, 11, 1644-1663.

https://doi.org/10.4236/health.2019.1112125

Received: November 19, 2019

Accepted: December 27, 2019

Published: December 30, 2019

Copyright ( 2019 by author(s) and Scientific Research Publishing Inc. This work is licensed under the Creative Commons Attribution International License (CC BY 4.0).

http://creativecommons.org/licenses/by/4.0/

(c) (i) Open Access

\begin{abstract}
A number of prominent solution-focused brief therapists have expressed the view that, to its detriment, this school of therapy tends to downplay emotion. Accordingly, we contend that, given that emotion is a primal binding force, the bonding component of the crucially important therapeutic alliance risks being compromised in the current practice of this approach. We further argue that the prioritization of the depiction of actions that accompany the emotion expressed by the client over the actual participation in this emotion by the therapist tends to superficialize therapeutic communication. This is especially likely to happen when the therapist lapses into a formulaic, actionsoliciting interrogatory mode in response to the emotion expressed by the client. In addition, we claim that the incorporation of emotion- and bodybased approaches into the solution-focused canon could remedy the affective lacuna referred to above. We note, however, that such a modification would most likely face stiff resistance from some of the gatekeepers of solution-faced therapy, in particular those who subscribe to the "surface-only" descriptive approach advocated by the philosopher Ludwig Wittgenstein. And yet, the effectiveness of depth-oriented therapies, such as sensorimotor psychotherapy and somatic experiencing, is supported by neurophysiological considerations. Finally, we suggest that these therapies, and even creativogenic elements of psychoanalysis, can actually synergize solution-focused brief therapy through the generation of affect-laden images, sensations and thoughts that lend themselves to the realization of outcomes desired by the client, which is the raison detre of solution-focused brief therapy. This paper
\end{abstract}


pleads for the incorporation of the above-noted depth approaches into solution-focused brief therapy with a view to augmenting its effectiveness through a stronger therapeutic bond owing to an increased emotional engagement on the part of the therapist.

\section{Keywords}

Solution-Focused Brief Therapy, Emotional Creativity, Surface-Only Approach, Sensorimotor Psychotherapy, Somatic Experiencing

\section{Introduction}

Solution-focused brief therapy (SFBT) features a pragmatic, minimally theoretical, outcome-oriented approach to psychological problems. It appeared on the therapeutic scene in the late 1970s. Its primary founders were Steve de Shazer and his wife Insoo Kim Berg, who worked closely with a small circle of other therapists who were dissatisfied with the state of the art at the time, often with its psychodynamic bent [1]. The following were among the foremost influencers with respect to this school: the hypnotherapist Milton Erickson, who was noted for his minimalism, his non-pathological orientation, his abiding faith in the ability of clients to exit their problems, and the importance he attached to what he called the creative unconscious; the anthropologist Gregory Bateson, who stressed the ecological harmony of the world and the importance of patterns of communication; and the Mental Research Institute, whose staff introduced radical innovations into brief and family therapy. The cornerstones of SFBT could be said to be hope, a desired-future orientation, client strengths and other resources, and minimalism (less is more). Iveson et al. [2] have summarized the aims of SFBT as follows: "to look for resources rather than deficits; to explore possible and preferred futures; to explore what is already contributing to those futures; and to treat clients as the experts in all aspects of their lives." [2].

A number of prominent practitioners of SFBT have commented in the literature that this approach downplays emotion in favor, for example, of a formulaic asking of questions designed to elicit from the client a depiction of a desired future. In this paper, we explore how this state of affairs might have come about. Prominent among the probable reasons is the far-reaching influence of the philosopher Ludwig Wittgenstein, especially through his insistence on a "surface-only", descriptive orientation-not only on the primary founders of SFBT but also on a significant number of their opinion-making followers down to the present day ${ }^{1}$. More important than the origins and perpetuation of this trend are its implications for the effectiveness of SFBT. In particular, we suggest that for ${ }^{1}$ Interestingly, although de Shazer was impressed and influenced by the revolutionary and unconventional methods introduced by Milton Erickson, for example, the brevity of his therapies, neither he nor his followers seemed to attach any (formal) importance to the "creative unconscious", a concept that Erickson cherished and was key to his way of working and his inspiration. Indeed, it did not fit with their enshrinement of a surface-only, anti-depth approach. 
some clients, for example, those with complex or developmental trauma or those who require a deep emotional engagement from their therapist, the relative emotional shallowness of SFBT might compromise the all-important factor of the therapeutic alliance.

Further, we discuss what we consider to be a vital distinction in psychotherapy, namely the distinction between the so-called top-down and bottom-up approaches. By the former, we mean predominantly cognitive approaches, i.e., talk therapies, which recruit primarily the neocortex, and by the latter, approaches that target the emotional or limbic brain, and the reptilian brain (reflexes, instincts, automatisms) through appeals to the body (movement, posture, sensation, emotion, sensory input and output). We discuss the claims of leading body-oriented therapists that exclusively top-down approaches are not sufficient or are not likely to be sufficient for the treatment of severe trauma; however, we also discuss claims to the contrary by a prominent SFB therapist. We go on to propose the radical idea (for SFBT purists) ${ }^{2}$ that in certain cases, SFBT could benefit substantially from an enlargement of its vistas to include body-oriented, bottom-up approaches and even elements of psychoanalysis, i.e., primary-process phenomena. The core idea underlying such an integration is that material worked up from where it is neuronally "trapped" in the emotional brain can be nicely processed and topped up in typical SFBT fashion. It is, in particular, the intensity with which such material emerges that lends itself to SFBT processing, this eruption being frequently accompanied by flights of creative solution-building imagination $^{3}$. We contend that the incorporation of certain approaches that are traditionally foreign to SFBT could save it from fossilization, i.e., the absence of creative growth beyond its present confines owing to the persistent adherence to outmoded dogma.

\section{Emotion and Emotional Creativity}

Without appropriate emotional interactions between client and therapist and an appropriate emotional climate as a consequence of these interactions, there is a serious risk that relational creativity, relational movement, and ultimately, the therapeutic alliance will be stunted. After all, in the therapeutic context, relational creativity is all about creating or building a relationship with clients that will help them to get to where they want to go. It requires of the therapist more savoir etre (knowing how to be) than savoir faire (knowing how to do). We will

${ }^{2}$ The first author first came across this term in a conversation with an SFB therapist affiliated with a leading training center who characterized the (non-integrative) approach of his organization in this way.

${ }^{3}$ Contemporary SFBT makes a critical distinction between problem-solving and solution-building. In short, the former implies a problem orientation, with all that that entails, for example the quagmire effect, which can fatigue both client and therapist, and hinders flights of creative imagination. In contrast, solution-building, based as it is on the client's goals and desired outcome, which may morph considerably during therapy, frees up this imagination. As a consequence, life is injected into the therapeutic process and frequently the presenting problem becomes irrelevant. This development may enable the emergence of undreamt of possibilities, which makes SFBT an inspiring undertaking. 
therefore now explore the topic of emotion in the therapeutic context.

Therapeutic emotional creativity could be defined as the co-construction of felicitously interacting feeling states underpinned by the client's perception that the therapist is deeply and emotionally involved in her or his situation and is driven by a need to help the client. In other words, the phylogenetically evolved helping instinct must come to the fore in therapists in order for them to connect emotionally with their clients. In addition, to set up an effective emotional climate, therapists must demonstrate to their clients that they are authentic, i.e., they must not ape another therapist, suffer from a compulsive addiction to a protocol or ply their trade primarily for financial gain.

A number of prominent SFB therapists proffering differing views have addressed the question of emotion in SFBT. King, for example, suggests that "...greater utilization of affect (grounded in bodily senses), as evoked in both client and therapist, can offer valuable clues to determining focus/goal setting, and thereby expedite our clinical practice." [3]. We find the idea of the grounding of affect in the bodily senses particularly relevant to the improvement of SFBT and will address this topic in the section "Expanding the Vistas of Solution-Focused Brief Therapy." According to Kiser et al., "The role of emotion in solution-focused therapy has been neglected. Instead, solution-focused therapists have primarily concentrated on the cognitions and behaviors of their clients." [4]. Referencing Steve de Shazer, the primary founder of SFBT, the authors go on to state that, "Unlike de Shazer (personal communication, January, 1987), we believe that emotions should be overtly incorporated into the goal-setting process." [4]. Five years later, King corroborated this view, elaborating it considerably as follows [3]:

In solution-focused therapy literature, there are few direct references to emotion. The emphasis is building on clients'strengths and workable goals via a future orientation. Discussions of emotion may be considered within the frame of "problem talk", and hence, are not to be encouraged. Many brief therapists fear that evoking emotions will strengthen the connection between therapist and client, making it harder to end therapy. There appears to be an implicit view that expressing feelings may help people feel better in the moment, but will not be significant in promoting lasting change.

The following excerpt from an SFBT session conducted by Iveson illustrates the extent of the discrepancy between the orthodox view of SF and ours (see further) on what the role of emotion should be in SFBT:

"Like many in our field, I ve never really understood where this idea comes from that SFBT doesn't talk about emotions (inner experiences, not'things'). Yesterday, in response to a client's statement, I asked, 'What difference might that make? 'P d feel so much more confident!', said the client as her head lifted and her shoulders relaxed. 'How would your baby know that you had woken up feeling so much more confident?' 'P d want to pick him up and hold him.' 'What would he notice about the way you picked him up that fitted with this wanting?' 'It would be gentle and I d be talking to him.' 'Would he like that?' 'Yes.' 'How would you know?' 'He'd hold me tight.' These interchanges are full of emotion; 
the task of the SF therapist is to help the client simply to describe the actions which go with the emotions. it is these action-describing (on-the-surface) words that create new possibilities." [5].

In this excerpt, the responses of the client are certainly full of emotion. but can we actually talk about an exchange of emotion between therapist and client, given that the therapist's interventions here, in accordance with an SFBT principle, are geared to incite the client to describe actions and set scenes that fit with the emotions that she is expressing, and apparently not much more than that? Here, the therapist-at least as far as we can detect-does not appear to engage with the client in her (deep) emotional space.

The important issue in this regard is the extent to which the absence of emotional expression, deep or superficial, by the therapist in a surface-only, depiction-of-action approach that relies largely on inquisitive-we could even say compulsive-questions might inhibit bonding in the therapeutic alliance with some clients, thereby interfering with therapeutic effectiveness, as stated above.

\section{De Shazer on Emotion}

Lipchik asserted that "If solution-focused therapists assume change occurs through language, and that is understood to mean no more than asking questions, disappointing results are probable." [6]. Miller and de Shazer rebutted her view as follows:

Central to therapists' use of emotions as a second-order construct is their differentiation of emotions from other aspects of self, social relationships and therapy. Usually, this involves distinguishing emotions from the cognitive and behavioral domains, the latter categories refer to persons rational processes and observable actions, respectively. This otherwise straightforward differentiation is the first step in casting emotions as a distinctive domain of therapist interest, one that is defined by its nonrationality and our inability to observe it directly. Emotion-oriented therapy promises to take therapists inside of themselves and their clients, as well as to provide them with new mysteries that cannot be imagined-much less talked about-by therapists who content themselves with matters of the exterior [7].

This article deserves additional attention because it is co-authored by de Shazer and thus, in principle, should reflect his attitude to emotion. The notion of the differentiation of emotion from cognition and behavior that the authors refer to and categorically reject is particularly interesting in that they claim that in SFBT, emotions, presumably along with primarily cognitive outcome-oriented questions, should be subsumed under the umbrella of the SF "language game". ${ }^{4}$ They contend further that emotions, like language, are activities, i.e., we do them through certain behaviors, for instance, crying. They agree that we feel emotions but maintain that in attempting to explore feelings for their own sake as an entity separate

${ }^{4}$ This is a Wittgensteinian concept the point of which is that all forms of language, i.e. of communication, are bound by rules (just as games are). The SF language game would therefore be a game the object of which is to facilitate the generation of an outcome desired by the client. 
from (observable) behavior, therapists (which ones?) engage in "mysterious, private, and nonsocial aspects of therapy relationships" [7]. Instead, they argue that emotion should be dealt with in accordance with the language game whose rules govern SFBT. These rules constitute a (social) system of communication the object of which is to facilitate solutions, for example, by injecting into the dialog feelings conducive to an optimistic mindset. Connie holds a view of emotion that is consistent with that of Miller and de Shazer and takes their thinking one step further: "It has been a long-standing thought that the solution-focused approach does not address emotions in working with clients. However, this thought is completely untrue and an idea that needs to be addressed. When using the SF approach, emotions become true experiences on behalf of the client drawn about by the preferred future (or past) descriptions." [8]. In our view, in this scheme, it is not clear how "truly", or rather how emotionally, the therapist's interventions reflect the client's emotional experiences.

One of the consequences of the stance taken by Miller and de Shazer, and Connie, is that, in SFBT, it is unproductive to dig for emotions in order, for instance, to flesh them out or find their "origin", as in emotion-focused therapies and psychoanalysis. However, this insistence on the non-productivity of a depth ${ }^{5}$ approach to emotion and on the fallacy of ultimately differentiating between emotion and cognition does not align with neurological reality as expounded, for example, in MacLean's triune model of the brain, which predates Miller's and de Shazer's paper by some fifteen years [9]. This model posits precisely the differentiation of the cognitive from the emotional that these authors deny, and this on the basis of demonstrable anatomical structures and physiological functions of the brain, and not at all, of reified abstractions (see below: Expanding the Vistas of SFBT).

We conjecture that some world-class, opinion-making SF therapists and their pupils do indeed distinguish between cognitive language (largely through questions) and emotional language (especially the language of intense emotion), but not for the reason cited by Miller and de Shazer and not for the right reasons, i.e., those, for example, having to do with the triune brain. We believe that they make this distinction because they have inherited a tradition emanating from the founders of SFBT that tends to downplay emotion and "upplay" cognitive questioning. This assertion is buttressed by Kiser's statement in his doctoral dissertation, which was based on in-depth interviews with the co-founders of SFBT, that one of his interviewees, i.e., a member of de Shazer's inner circle, felt that "de Shazer enjoys, and even prefers, intellectual discussions because of his uncomfortableness with his own and others' feelings. S/he (the interviewee) speculated that when these individual relationships became more intimate, de Shazer became uncomfortable. In response, de Shazer curtailed contact and sought out someone else to resume theoretical discussions with." [10]. Finally, in a Face-

${ }^{5}$ Depth could be taken to refer to factors like the nuances of emotion, intuition, "the unconscious", and ideas that are stored in the body's motor and perceptual systems or that arise from the body's interactions with living and non-living entities in the environment (embodied cognition). 
book interview, Lipchik-a member of de Shazer's pioneering entourage-recounted that before he started a therapy session, de Shazer would remove kleenex from the room lest the client should start to cry at some point [11]. These anecdotes could suggest that the degree to which therapists relate to their clients emotionally is largely independent of the school to which they adhere, and depends instead, on the extent to which they are at home with emotion-both their own and their clients'. As Miller (S. D.), Hubble, and Duncan put it, "We know that who provides the therapy is a much more important determinant of success than what treatment approach is provided." [12]. These anecdotes might also mean that the avoidance of deep emotional exchanges in SFBT cited above by King and Lipchik is rooted firmly in, and has most likely filtered down transgenerationally from, de Shazer's personal attitude to emotion.

In our view, none of the (highly philosophical, distinctly unemotional) arguments made by Miller and de Shazer refute the opinion of Kiser et al., and of King, that emotion had been neglected in SFBT, i.e., up to the time of writing [3] [4]. None of the considerable number of SFB therapists (a few of whom were in close contact with de Shazer and adhered to his ideas) with whom the first author has come into contact through hundreds of postings over several years on an international SF discussion forum (http://SFT-L@listserv.icors.org), hereafter referred to simply by its email address, indulge in obscurantist theories of the type alluded to by Miller and de Shazer about the private experiences that underlie clients' emotions. In fact, they are allergic to such theories. It is therefore difficult to understand how Miller's and de Shazer's assertion that emotionally focused therapists do indulge in such theories applies to the above-noted views on the de-emphasizing of emotion in SFBT expressed by Kiser et al. and King. Exactly as Miller and de Shazer suggest that they should do, in engaging with clients' feelings, contemporary SF therapists-at least the broad, international sample who post on http://SFT-L@listserv.icors.org_rely on the external signs of their clients' emotions and the social context in which they are embedded. We would therefore qualify these authors' rebuttal of the critique by Kiser et al. of the orthodox view of the role of emotion in SFBT as much ado about not much [4] ${ }^{6}$.

\section{Expanding the Vistas of Solution-Focused Brief Therapy}

If it is accepted that the purist version of SFBT imposes limitations on the depth of emotional communication and also on attention to somatic manifestations and thus might prevent SFBT from realizing its full therapeutic potential with some clients, it could be asked how the integration of body-oriented therapeutic approaches into the practice of SFBT could synergize the latter for certain therapists, certain clients and certain classes of problems. We have said, "If it is accepted", so why should this critique of SFBT be accepted? After all, Bannink, for example, with references to back her up, reports that SFBT is effective in a broad variety of

${ }^{6}$ It may be objected, however, that this sample, broad as it is, is characterized by a selection bias, so that Miller's and de Shazer's argument applies to other SF therapists, who do not share the views of this sample. If so, the questions arise of who they are and where they are to be found. 
disorders, including alcohol abuse, posttraumatic stress disorders, personality disorders, and psychoses [13], and she is not alone in making such a claim, this view having been expressed periodically by SF experts on

http://SFT-L@listserv.icors.org. On the other hand, she states as a contra-indication (rarely if ever discussed in the SF circles with which the first author is acquainted) the inability to hold a conversation, as in acute psychosis and severe depression [13]. Presumably, it would be difficult in these cases, if not impossible, to get answers to questions. A possible way out of this impasse might consist of dosing the quantity and quality of questions as a function of the client's affective receptivity to them, which must be gauged carefully. The first author has never encountered this all-important point in any of many discussions among a variety of SFB therapists. In any event, we suggest that more importance be attached to creating a deep emotional bond with clients, including their bodies, as opposed to incessantly trying (sometimes straining) to come up with the next (largely cognitively oriented) question to put to them [14] [15], thereby sometimes rendering them as mere objects of interrogation. We believe that if such were the practice, more could be done, and this, ultimately through SF methods, to help clients for whom purist SFBT does not work or has not worked, especially in the area of trauma. Furthermore, in our view, the group of contra-indicated clients might be comprised of more than acutely psychotic or severely depressed persons; it might also encompass chronically over-aroused, emotionally dysregulated, dissociated persons with severe attention deficit, and developmentally traumatized persons. Such individuals, when asked to depict a preferred future, sometimes have so much trouble recruiting the imagination and hope (hallmarks of SFBT) needed to do so that it is impossible for them.

Accordingly, we ask the following question: Why should primal life forces like emotion and body contact, whose dramatic bonding effects are seen, for example, between mothers and their infants, guide dogs and their owners, dolphins and autistic persons, etc., be, a priori, relegated to the background in a psychological therapy? Coaxing a smile from an infant, the anxious, expectant look on the face of a dog tethered to a pole while she waits for her master to exit a supermarket-all these interactions and responses are manifestations of attachment, which has been the subject of many empirical investigations, witness, for example, the discovery of the secure-attachment action of the hormone oxytocin [16]. In addition, the biological basis of emotion and human relationships has been laid bare by a number of researchers. Panksepp, for example, investigated the neural mechanisms of basic emotions common to humans and non-human animals, and in so doing, founded affective neuroscience [17]. In a transformational contribution to psychotherapy, Siegel pioneered a field known as interpersonal neurobiology, which features an interdisciplinary approach to psychotherapy that brings together various scientific fields [18], i.e., not merely brain science in all its neuronal complexity but also a number of non-scientific ways of apprehending the world, and this with a view to distilling common principles as a means of understanding and therapeutically remodeling human experience. 
Among the therapeutic aims of this approach is the replacement of hardness, chaos and rigidity with compassion, integration and flexibility. It is to be noted that these concerns are of a significantly broader order than those of SFBT. The underlying philosophy of interpersonal neurobiology is so holistic and unitive that one could actually speak of a blurring of boundaries between disciplines, for instance, between complexity theory, neurology, and spirituality.

We agree with Wittgenstein that a consensus about emotions can be achieved on the basis of behavioral correlates, but so what? In light of the scientific developments just cited and others, we do not agree with Miller and de Shazer, who, largely on the basis of Wittgenstein's teachings, assert or imply that what they describe as the non-verifiable, mysterious nature of private, i.e., internal, emotional experiences, should put SF therapists on their guard about how they deal with emotion in actual clinical practice [7]. Nor, perhaps paradoxically, do we accept that their position that the use of emotion in SFT should adhere exclusively to the rules of a solution-seeking language game necessarily provides the best or most efficient route to solutions! After all, there are clients who are so desperate and sensitive that they would not be willing or are not able to play this game, based as it is on a barrage of "emotion-light" questions. Instead, such clients might require a deep, empathic sharing of their turmoil with their therapist in which perhaps no questions at all would be asked and not a single word uttered-still moments of truth in an interpenetration of gazes. We suspect that the Wittgenstein-inspired warnings implied by Miller and de Shazer have led to the widely accepted attitude to emotion held by contemporary prominent SF therapists, such as Connie, who takes the view that "...it is quite clear that emotions are not to be addressed in the traditional fashions by asking things like, 'How does that make you feel?' or by asking similar questions that elicit a description of one emotion or another." [8]. If one adds to this understanding of the role of emotion in SFBT Connie's position, stated above, that in SFBT, emotion serves largely as a springboard for depicting the client's preferred past and future, it is but a stone's throw from high jacking emotion through the formulaic asking of questions in line with Connie's view of SFBT as a "questions method" [15].

On the other hand, in a vibrant life, both outside and inside therapy, emotions are to be lived to the full and not philosophized away through intellectual abstractions. Such is our prejudice. The neuroscientific progress referred to above renders obsolete Wittgenstein's misgivings (anxiety?) about the non-verifiability and internal locus of emotions and his insistence on a surface-only approach to affective phenomena. The arcane territory that his philosophy shuns has been all but eliminated by the inroads of science. Consequently, this aspect of his thinking should long ago have become a historical relic for SFB therapists instead of dominating many of them as it continues to do today, anachronistically. If purist SF therapists, in their enthusiasm for Wittgenstein's philosophy, were to adhere to Nietzsche's assertion that "philosophy must start from a proper understanding of the body." [19], their current conception of SFBT, in which emotion and 
the body play only a secondary role, might undergo a radical transformation. Note that in all the cases of emotional interactions and responses cited above, the neocortex, whether of human infants or non-human animals, is not developed, so that communication necessarily proceeds predominantly via the emotional brain. And how moving, non-cognitive, relationally creative, sustained, and unconditional such communication is!

As Miller (S. D.), Hubble and Duncan pointed out in an article on the success factors of "supershrinks", "Where we as therapists have the most impact on securing and sustaining engagement is through the relationship with our clients, what is commonly referred to as the 'alliance'. When it works well, client and therapist reach and maintain agreement about where they are going and the means by which they will get there. Equally important is the strength of the emotional connection-the bond (Italics added)." [12]. The importance of the therapeutic alliance, and in particular, the bond component of the therapeutic alliance, regardless of the school of therapy, cannot be overestimated. According to a meta-analysis conducted by Horvath et al., this alliance accounts for " $57 \%$ of the variance of the effect size over and above random (chance) variation", i.e., the lion's share of therapeutic effectiveness [20].

As for the question raised above, namely how the integration of body-oriented therapeutic approaches into the practice of SFBT could help to overcome the limitations that we believe are imposed by its largely cognitive approach to therapy and relatively shallow approach to emotion, it is instructive at this point to bring in MacLean's triune model of the brain [9]. According to this conceptualization, the human brain is divided into three "part brains": the neocortex, the mammalian brain, otherwise known as the emotional or limbic or midbrain, and the reptilian brain. The first regulates cognitive processes, including reasoning, abstraction, planning, problem solving, thoughts, beliefs, insights and reflective function, the second, subjective feelings and emotional memories and responses, and the third, movement (along with the frontal lobe), sensory perception, instinctual behaviors and reflexes, i.e., automatisms in the service of survival. The part brains are interconnected by multiple neuronal pathways and a change in one of these, for better or for worse, induces corresponding changes in the others through a cascade effect. For example, in trauma, the monitoring and analytical ability of the neocortex can shut down in response to emotional and sensorimotor triggers arising from the emotional and reptilian brains, or, on the other hand, the emotional brain can be overridden by the cognitive brain, which leads to parasitical thinking and emotional numbness.

Despite the SF penchant for "positive" thinking, these pathological conditions do exist, and according to Levine, the founder of a biophysical trauma therapy known as somatic experiencing, and Van der Kolk, a ground-breaking neurologically oriented trauma researcher and therapist, it is highly doubtful that trauma, presumably beyond a certain severity, can be dealt with effectively through what these therapists call a top-down approach alone, i.e., a so-called talking cure of any description in which, by definition, sensorimotor perception and movement 
are of no intrinsic interest and the emotional brain is undervalued, the primary appeal being made to the cognitive capacity of the neocortex. They posit that, in the first instance, what is needed to relieve trauma is a bottom-up approach in which bodily manifestations, such as posture, movement, sensations and sensory experience, and the emotions and thoughts that accompany these, are given primacy [21] [22] [23]. As for movement, as part of a bottom-up approach, Van der Kolk promotes breathing, yoga and even theater (whole-body activity) as being effective in trauma [24]. On the other hand, Ogden and Fisher, who are pioneers in the development of sensorimotor psychotherapy, seem to advocate a synthesis of the bottom-up and top-down approaches [25]. Post-modernist, purist SF therapists would most likely contend that the notions of top-down and bottom-up are not useful, and perhaps not even valid, as they are reifications of a mentalistic abstraction. In addition, these concepts do not fit with their insistence on a surface-only approach. As implied previously, however, neurobiologically oriented therapists would argue that, on the contrary, the distinction between top-down and bottom-up is grounded in the anatomy and physiology of the brain.

Advocating the top-down, surface-only, depth-shy (and possibly problem-shy) approach to trauma, Furman, an SF therapist known for his particularly creative contributions to child therapy, takes the (Wittgenstein-derived) view that "understanding the roots and causes of problems" is counterproductive [26]. In classic SF fashion, he contends that if a client wants to go this route, the following tack should be taken:

Imagine that one day in the future he (the client) has healed from his experience and that he feels so relieved that he wants to celebrate his healing in some way. Helping your client to develop a detailed fantasy of such a celebration is a subtle and pleasant way to generate hope and activate your client's own resources.

In addition, he has compiled a set of questions that target the client's gratefulness to the people who helped him at the time of the traumatic event, thereby tapping into the spiritual aspect of the trauma. His questions about the possibility of the client's helping others who have had a similar experience fulfill the same function, this time by way of transcendence.

As for traumatic intrusions into the field of consciousness, in vintage top-down, cognitive fashion, he advises:

If your client suffers from nightmares, flashbacks or intruding memories related to his adverse experience, you can explain to him that intruding memories tend to change over time. Tell your client that usually intruding memories become less intense, less disturbing or more neutral with time. If your client accepts your view, you can now help him accelerate the process by asking him how his nightmares, flashbacks or intruding memories have already changed and how he imagines that they will continue to change with time.

It is apparent that Furman's SF approach to trauma contrasts stridently with Levine's and Van der Kolk's body-based methods. On the other hand, the senso- 
rimotor sequencing technique used in sensorimotor psychotherapy offers an intriguing answer to the question raised at the beginning of this section, namely, how could the incorporation of a body-oriented therapeutic approach into the practice of SFBT overcome the limitations that we claim it has in certain cases? The following example of the application of the sequencing technique is adapted from a case presented by Ogden and Fisher [25]. The therapist asks a client manifesting severe panic (emotional brain) to put the panic aside and focus intensively on her trembling (sensation, reptilian brain). The client is then asked to describe the trembling in detail without any reference to the thoughts (cognitive neocortex) around the traumatic scene in which they first arose. Next, the client is requested to complete a movement (reptilian brain and frontal lobe) that seems to be urged by the trembling. It might turn out that the movement is a defensive response to the perpetrator of an aggression-one-off or repeatedthat the client was powerless to make at the time. This new-found ability to cope with the aggression, accompanied by insight (cognitive neocortex) into the objective helplessness experienced at the time of the assault, might bring about pleasureful satisfaction (empowerment, emotional brain). In the best of cases, this sequence of events results in the restoration of the cognitive brain's timekeeping ability, i.e., the critically important ability to distinguish what was (powerlessness) from what is (power, self-efficacy), which is no small feat on the part of the cognitive brain and, again, could well be a source of satisfaction or even pride for the traumatized person. In the mobilization of the triune brain, the interventions just described are a far cry from the classic, relatively "bodiless", primarily cognitive approach of SFBT. Nevertheless-and this point cannot be emphasized enough-not only may they help the client to build an impressive solution or discover an outcome far removed from the presenting problem in a time frame that is as brief as that of classic SFBT, but also they are perfectly compatible with a conventional SFBT processing of the transformations generated by the sensorimotor psychotherapeutic approach.

Once the products of the client's bodily resources start pulsating powerfully through the triune brain, affect-laden images and metaphors sometimes facilitate the emergence of imaginative strategies that lend themselves to future-oriented solution building or even the dissolution of problems as the initial presenting problem recedes to the background. Such is the way of SFBT. This process could be described as a solution-focused topping up of the fruit of a body-oriented bottom-up workup. A similar phenomenon can occur with eye movement desensitization and reprocessing (EMDR), which also utilizes somatic stimulation (bilateral stimulation of the eyes or, alternatively, of the ears or knees).

Such a process lies at the core of the main argument of this paper, which advocates a synthesis between classic SFBT and body-oriented approaches, which are outside this school. We are not claiming that SF therapists, en bloc, refuse to work with non-SF methods in which one or other notion of depth plays an important role. Indeed, the center in which the first author was trained in SFBT embraced such methods while retaining an overall SF framework. In addition, 
this author is acquainted with a few intellectually adventuresome, dogma-resistant colleagues who have seen fit to augment the effectiveness of their SFBT practice by integrating other approaches into it. What we are asserting is that some highly influential, trend-setting SF therapists stick to a (surface-only) dogma in which, by definition, depth (both emotional and neurophysiological) is not considered to be a useful concept. These therapists do not necessarily deny the existence of depth; rather, their position seems to be that the current SF toolbox is not equipped to work with it, or else that it is not efficient to do so (minimalism). It would therefore be interesting to conduct an analysis of SF failures as part of an effort to ascertain if the kind of synthesis we are proposing might have worked in at least some of the cases that have failed.

As for the competing claims about the necessity, in some instances of severe disturbance, of a bottom-up approach versus the adequacy of a top-down method like that practiced in SFT, it is possible that the answer lies not so much in the school of therapy as in the therapist's self-confidence and conviction that her or his approach is in fact effective-a conviction that could well infect the client and also act as a self-fulfilling prophecy. On the other hand, bottom-up therapists might argue that it is doubtful that without the prior appeal to the "guts" of the brain, i.e., through priming the midbrain and the body as a whole, especially in trauma work, answers to a volley of top-down, (at times) distinctly affect-poor SF questions could be co-opted into the sculpting of the kind of solutions, dissolutions and resolutions achieved when the whole body, as opposed to mainly the cognitive brain, is brought to bear on the healing process.

And the vistas of SFBT could be expanded in yet another way. In the experience of the first author, who has been trained psychoanalytically, SFBT can also be enhanced through the integration of primary-process phenomena in the form of dreams and hypnagogic manifestations such as images, verbal productions (on the face of it, gibberish) and sensations. These phenomena sometimes furnish crucial insights into the actual mechanisms of creativity unfolding in a sleeping or sleepy individual. In fact, they can set the stage for the repair of creative processes that have become snagged. The mere occurrence of a creative setting or background (music, art, invention, etc., in line with the dreamer's life pursuits) in an otherwise conflict-laden or even horrific dream sometimes indicates that the dreamer's creativeogenic antibodies have been activated and are waging a battle against her or his psychic infection. A case in point is Kay Wilson, whom the first author personally interviewed about a terrorist attack in which she was nearly hacked to death in a forest, and her friend, who was a few feet away from her, was hacked to death [27]. At various points during her painful recovery process, she conjured up images of great creators and creative works, such as Einstein, Oscar Peterson, The Wizard of Oz, and the song Over the Rainbow, and went on to beautifully transcend her ordeal, for example, as a motivational speaker, a writer, and an advocate of anti-terror measures.

Therapists who detect such a creative development in a client are then given the opportunity to align themselves with their clients' solution-generating efforts 
in this noble struggle. In this way, the therapist may be able to join the client in an SF self-healing, self-correcting process. Coded resource-filled messages conveyed by creativogenic dreams and images, especially in crisis periods in a client's life, can be unraveled by the simple psychoanalytic technique of free association and then used for solution-building purposes. Needless to say, such a technique is incompatible with a surface-only approach, which, by definition, denies "the unconscious". And yet it is not at all incompatible with a solution or outcome focus.

\section{Wittengenstein's Heavy Footprint}

Whether or not Wittgenstein influenced de Shazer in his thinking about the surface-only stance, the use of language (language games), the role of emotion, and possibly minimalism, there is a substantial confluence of his and Wittgenstein's ideas on these topics. It is noteworthy that in the article referenced above on emotion in SFBT by Miller and de Shazer himself, the authors cite Wittgenstein no fewer than 21 times regarding causality, rules, verbal contexts, the behavioral manifestation of emotions-they introduce the latter topic with the phrase, "As Wittgenstein teaches us" [7] - the unverifiability of internal, private experiences, and therapeutic approaches as being subject to the rules of language games. It is also a fact that Wittgenstein is periodically discussed on http://SFT-L@listserv.icors.org. Now and then, too, Wittgenstein’s writings are talked about in the Journal of Solution-Focused Brief Therapy. For example, in this journal, Drury [28], an SFB therapist and a Wittgenstein scholar, stated in an article titled "A Taste of Wittgenstein for SFBT. 1: The Tractatus" that, "Wittgenstein holds a special place in Solution-Focused Brief Therapy" due to his idea that "...problems are solved in the literal sense of the word-dissolved like a lump of sugar in water" [29], which may be relevant to the insistence of this school of therapy on a solution-building or problem-dissolution vs. a problem-solving approach. Finally, propositions from Wittgenstein's Tractatus Logico-Philosophicus were explicated by a Wittgenstein specialist in the course of the first author's SF training curriculum in 2009 [30]. Consequently, it is clear that Wittgenstein's philosophy, in various ways, left a heavy footprint on SFBT, and that this footprint has persisted undiminished until today. We take the trouble to point out the evidence of the Wittgensteinian influence on SFBT because we maintain that some of these influences impose limitations on the power of the approach in some-certainly not all-situations.

It may be a contradiction that purist SF therapists-who are particularly concerned to minimize their footprint on their clients post-therapy so as not to render them dependent on them-seem themselves to bear a heavy and persistent footprint emanating from Wittgenstein's philosophy [31]. It is noteworthy that whereas Wittgenstein railed fiercely and creatively against the doctrines of philosophy and science (and psychoanalysis) that held sway in his time, as far as the authors know, no SFB therapists upon whom Wittgenstein's legacy has not cast a spell challenge the wholesale adoption of his doctrines by certain promi- 
nent gate-keeping SF therapists [32]. It might be asked whether groupthink is at play here. In any case, one might have expected at least some of the free-thinking therapists to have done so given the possible limiting effect of some of Wittgenstein's ideas on the effectiveness of SFBT in certain situations that we claim. We will now proceed to take up such a challenge.

If we take Wittgenstein's surface-only orientation, for instance, it is obvious that it threads its way deeply through the rationale underlying SFBT, impacting doctrinally, we would even say, on the practice of SFBT, as the following statement by Iveson et al. illustrates: “The 'fit' (with the client) that SF practitioners seek is around a description of the client's aspirations, not an understanding of the client's problem..." [33]. Descriptions of hoped-for action scenarios are the modus operandi of contemporary SFBT; under Wittgenstein's influence, understanding falls by the wayside. In what was perhaps an extreme moment, the philosopher affirmed that, "We must do away with all explanation, and description alone must take its place." [34]. With this declaration, Wittgenstein anticipated post modernism, which de Shazer seems to have embraced wholeheartedly, witness the following (penetrating) remark he is reported to have made during a lecture: "There is no such thing as understanding; there are only greater or lesser degrees of misunderstanding." [35].

Let us now return to the possible limiting effects of some of Wittgenstein's positions on the effectiveness of SFBT in certain cases. The first author agrees, on the basis of personal clinical experience and anecdotal reports from SFBT colleagues, that "top-down, surface-only" works beautifully in many situations. In addition, the effectiveness of SFBT is evidence-based [36]. As Yogi Berra might have said, however, (like all therapies) it works until it doesn't work. What recourse, then, do SFB therapists have when it doesn't work? The lock-stockand-barrel takeover of Wittgenstein's surface-only dogma by a number of opinion-making contemporary SF therapists, as evidenced in some of their online courses and some of their postings on http://SFT-L@listserv.icors.org, virtually outlaws any method based on a non-surface approach, for example, emotionfocused therapies. It could be concluded from Wittgenstein's teachings that the latter could or would get us into an unfathomable, arcane, abstract, and above all, unverifiable world of private experience, and are therefore to be avoided. The undoubtedly great philosopher seems to have been overcome by the epistemological angst of uncertainty when contemplating emotion independently of its observable behavioral correlates and social context. We believe, however, that the translation of such personal angst into hard-and-fast rules for the conduct of SFBT is an unjustified generalization from the personal to the community (of SF practitioners). One could ask, for example, whether the insistence on the description of actions that accompany emotion as the sole or main function of emotion in SFBT, as advocated by Iveson, does not significantly sometimes interfere with the flow of the "juice" of raw emotion between therapist and client-juice that, in some cases, lubricates the therapeutic alliance. 
Similarly, we have claimed above that an SFB therapist who is able to detect creativity-laden primary-process images generated by a client and to help the client, through psychoanalytic free association, to understand the meaning of her or his images, can, in this way, facilitate the client's solution-building ability, and this, let it be noted, within the SFBT framework. However, a number of tacit Wittgensteinian bans on such a procedure excludes it from SF practice. The prohibitions arise from the philosopher's reservations about the existence of a primary-process language and the possibility of interpreting it, about the existence of a hidden unconscious, and about the verifiability of the validity of the interpretation of dreams [32]. As a result, yet again, an opportunity for a synergistic SF topping up of depth material, and thus an extension of the field of application of SFBT, has been lost.

\section{Discussion}

Of central importance in this article is the possibility of a synergistic therapeutic effect achieved through a topping up by classic SFBT methods of emotionally charged images stimulated by body-oriented interventions traditionally outside the scope of SFBT. An argument is therefore made for the integration-no loose patchwork-of body-oriented (and emotion-) therapies into the SFBT toolkit. In order for this to happen, the enormous influence of some of the ideas of the philosopher Ludwig Wittgenstein on the development of SFBT would have to be countered. We believe some of his influence to be beneficial, even ingenious, and some of it, we think, has held this school of therapy back in certain clinical situations. In particular, we hold that certain of his beliefs and, hypothetically, certain aspects of his emotional makeup, have, across the generations, resulted in a tacit prohibition for SFB therapists on a full-bodied participation in the emotions expressed by their clients. These beliefs have to do with qualms he had about the arcane, unverifiable nature of internal affective states, and our sense is that these reservations were driven by epistemological angst, Wittgenstein's basic question in this regard seems to have been, how can we know anything [37]. His answer to this question was to adopt a surface-only, description-only, non-explanatory approach to various life phenomena-an answer that was taken over by the primary founder of SFBT and his followers. This solution, however, has segued into hypo-emotionality on the part of Wittgenstein-inspired SFB therapists. In our view, in certain circumstances, this constraint on emotional expression compromises relational creativity and the bonding component of the therapeutic alliance in the client-therapist dyad. The solution to this problem lies in one of the foundation stones of creativity, namely flexibility; we need to establish criteria that will enable us to know with what clients, what therapists, and what classes of problems a Wittgensteinian-de Shazerian surface-only, description-only approach is effective and in which of these categories it is not effective or less effective.

One of the benefits that the legacy of Wittgenstein has conferred on SFBT derives from his idea that words acquire the meanings that individuals attribute to 
them in particular social contexts. This position implies, for instance, that if a client embedded in western psychiatric culture states that she or he is suffering from "clinical depression", an SFB therapist will tend to ignore this diagnosis and instead ask the client precisely what she or he means by this term, which is likely to be different from what another client means by it. The client's meaning can then be explored with a view to helping her or him to build a solution or create a desired outcome. Outwardly-similar verbal suitcases are not helpful. The implications of this approach for therapy are immense: The therapist opens up to the client in all her or his splendid uniqueness as opposed to an impression of the client based on a pathologizing, distorting and highly limited and limiting conception imposed by a diagnostic manual. The therapeutic space now becomes pregnant with possibilities. The Wittgensteinian stance in this regard is profoundly idiographic and anti-nomothetic, and thus pro-therapeutic. In the same vein, if the not-knowing mode adopted by SFB therapists can be at least partially ascribed to Wittgenstein's reservations about explanations and what it is possible to know, then that must also be considered a good thing; thanks to this attitude, SFB therapists avoid the trap of foreclosure and, ideally, open up non-judgmentally to every thought, feeling and sensation that clients send their way. It is worth observing that avoidance of foreclosure is generally considered to contribute to creativity across domains.

The protocol of an emotionally shallow, surface-only, description-only approach excludes body-oriented and emotion-focused therapies from the SF canon. That is because these therapies frequently release intense emotion from the client, with which purist SF therapists tend to be uncomfortable and to which they cannot or do not respond in kind owing to their protocol (stated or unstated), and probably their personal inclinations too. Another, but related reason might be that the largely cognitive mindset of SFB therapists is not compatible with body contact, which is likely to occur between therapist and client in moments of heated emotion, for instance, in the course of sessions of somatic experiencing and relational eye movement desensitization and reprocessing. And that is a pity, since, as pointed out above, it is precisely such emotion that feeds neatly into further processing by conventional SF methods once it releases pent-up energy and helps to reconnect the affective, cognitive and somatic components of experience, thereby immensely facilitating the therapeutic process. Presumably, Wittgenstein-inspired SFB therapists would adamantly reject the notion of "pent-up energy" on the grounds that it is an unverifiable, reified, obscurantist abstraction. This largely philosophical objection, however, even if it is valid, in no way prevents the praxis of a synergy between the two modes of therapy in question as proposed in this paper. Similarly, Wittgenstein's doubts about the existence of a dream language has in no way prevented a host of psychoanalytic clients, and also many people in the non-clinical population, from deriving a therapeutic benefit from the interpretation of their dreams on the basis of such a language. In this respect, what Freud knew, Wittgenstein knew not, and what Wittgenstein knew, Freud knew not; each to his or her sensibilities. 


\section{Conclusions}

It is not favorable for the growth and creativity of a school of therapy, be it SFBT or any other, that some of the key concepts of a single individual-in this case, the undoubtedly brilliant philosopher Ludwig Wittgenstein-be given such a lofty status as to effectively exclude alternative therapeutic approaches, especially when the latter could bring about a synergistic interaction in the practice of the school in question. To allow such domination is to ignore the simple fact of the limitations of the individual, of differential emotional sensitivities across individuals, and also, of a possible non-fit between different disciplines, in this case philosophy and psychotherapy; in certain instances, a philosopher's meat could be a psychotherapist's poison. Creativity is a process that distributes across domains through cross-fertilization. Let us not forget this fact. Ludwig Wittgenstein's philosophy has made important contributions to SFBT but many individuals, hailing from diverse disciplines, must be admitted to the SF club in the coming years if the limitations of his philosophy are to be corrected and this school of therapy is to keep up with relevant developments in allied fields, for example, neuroscience. Fossilization owing to parochialism must be avoided at all cost.

The ideas that we have put forward in this article lead to a number of recommendations for the improvement of the practice of SFBT. We are fully aware that these recommendations constitute a momentous challenge to purist practitioners, mainly because they call into question a number of their firmly held convictions, in particular the surface-only, action-depiction approach advocated by Wittgenstein; the priority of questions over a full-bodied engagement with the client's emotions; misgivings about excessive problem talk; and the a priori exclusion of a direct approach to the body in favor of a cognitive talk (top-down) therapy. Furthermore, many-if not most-SF therapists would most likely contend that orthodox SFBT does not need to be synergized by a "foreign" school of therapy since it is already sufficiently effective.

Here are our recommendations:

- Training centers and gatekeepers should encourage therapists-especially beginning therapists - to feel free to dissent from prevailing dogmas and views. Therapists should never feel as if they were imprisoned in an ideological straitjacket, i.e., they must not feel oppressed by gatekeepers.

- Therapy training centers and discussion platforms should include material on allied disciplines, for example, neurobiology, art, sociology, cultural anthropology, ecology and spirituality (transcendence) so that therapists can acquire a broader perspective on their practice and cross-fertilize from these disciplines.

It would be interesting to test the hypothesis put forward in this paper, namely that the paucity of emotional expression on the part of the therapist and the relative inattention to bodily manifestations in the current practice of SFBT risk compromising the bonding component of the therapeutic alliance and thus the effectiveness of therapy. The test could consist of a quantitative comparison of 
two groups with respect to the strength of the therapeutic bond and the therapeutic outcome. The first group would be comprised of purist SFBT practitioners and the second of SFB therapists who integrate emotion- and body-based methods into their practice.

\section{Conflicts of Interest}

The authors declare no conflicts of interest regarding the publication of this paper.

\section{References}

[1] de Shazer, S. and Dolan, Y. (2007) More than Miracles: The State of the Art of Solution-Focused Brief Therapy. Haworth Press, Binghamton.

[2] Iveson, C., George, E. and Ratner, H. (2012) Brief Coaching: A Solution-Focused Approach. Hove, New York. https://doi.org/10.4324/9780203144411

[3] King, E. (1998) Role of Affect and Emotional Context in Solution-Focused Therapy. Journal of Systemic Therapies, 17, 55-64. https://doi.org/10.1521/jsyt.1998.17.2.51

[4] Kiser, D.J., Piercy, F.P. and Lipchik, E. (1993) The Integration of Emotion in Solution-Focused Therapy. Journal of Marital and Family Therapy, 19, 233-242. https://doi.org/10.1111/j.1752-0606.1993.tb00984.x

[5] Iveson, C. (2014) SOL Listserv Posting. http://SFT-L@listserv.icors.org

[6] Lipchik, E. (2002) Beyond Technique in Solution-Focused Therapy. Guilford Press, New York.

[7] Miller, G. and de Shazer, S. (2000) Emotion in Solution-Focused Therapy. Family Process, 39, 5-23. https://doi.org/10.1111/j.1545-5300.2000.39103.x

[8] Connie, E. (2013) Emotion in SFT. http://elliottconnie.com/emotions-in-sft

[9] MacLean, P.D. (1985) Brain Evolution Relating to Family, Play, and the Separation Call. Archives of General Psychiatry, 42, 405-417. https://doi.org/10.1001/archpsyc.1985.01790270095011

[10] Kiser, D.J. (1995) The Process and Politics of Solution-Focused Therapy Theory Development: A Qualitative Analysis. UMI Dissertation Services, Ann Arbor.

[11] Lipchik, E. (2019) SFP 34-Episode 34: Back to the Roots: A Conversation about the Beginning of Solution Focus with Eve Lipchik, ACSW, LMFT, LCSW. http://www.sfontour.com/project/sfp-34-back-to-the-roots-a-conversation-about-th e-beginning-of-solution-focus-with-eve-lipchik

[12] Miller, S.D., Hubble, M. and Duncan, B. (2008) Supershrinks: What Is the Secret of Their Success. Psychotherapy in Australia, 14, 14-22. https://doi.org/10.1037/e526322010-003

[13] Bannink, F.P. (2007) Solution-Focused Brief Therapy. Journal of Contemporary Psychotherapy, 37, 87-94. https://doi.org/10.1007/s10879-006-9040-y

[14] McKergow, M. (2016) SFBT 2.0: The Next Generation of Solution Focused Brief Therapy Has Already Arrived. Journal of Solution Focused Brief Therapy, 2, 1-17.

[15] Connie, E. (2017) The Questions Method: Asking Solution-Focused Questions That Produce Results. https://www.linkedin.com/pulse/free-video-training-series-questions-method-askin g-solution-connie

[16] Buchheim, A., Heinrichs, M., George, C., et al. (2009) Oxytocin Enhances the Exper- 
ience of Attachment Security. Psychoneuroendocrinology, 34, 1417-1422. https://doi.org/10.1016/j.psyneuen.2009.04.002

[17] Panksepp, J. (1998) Affective Neuroscience: The Foundations of Human and Animal Emotions. Oxford University Press, New York.

[18] Siegel, D.J. (2012) Pocket Guide to Interpersonal Neurobiology: An Integrative Handbook of the Mind. W.W. Norton \& Company, New York.

[19] Goldstein, K. (1995) The Organism: A Holistic Approach to Biology Derived from Pathological Data in Man. Zone Books, New York.

[20] Horvath, A.O., Del Re, A.C., Flückiger, C., et al. (2011) Alliance in Individual Psychotherapy. Psychotherapy, 48, 9-16. https://doi.org/10.1037/a0022186

[21] Levine, P. (2019) Resolution and Addiction Treatment. https://www.youtube.com/watch?v=gs-j0sxuCVM

[22] Levine, P. (2010) In an Unspoken Voice: How the Body Releases Trauma. North Atlantic Books, Berkeley.

[23] Van der Kolk, B.A. (2019) The Body Keeps the Score: When Talk Isn't Enough.

[24] Van der Kolk, B.A. (2018) The Masters of Trauma Treatment: Today’s Most Effective Interventions for Deep Healing.

[25] Ogden, P. and Fisher, J. (2015) Sensorimotor Psychotherapy. W. W. Norton \& Company, New York.

[26] Furman, B. (2018) Helping Clients Heal from Trauma: Solution-Focused Approach. http://www.benfurman.com/en/2018/05/23/helping-clients-heal-from-trauma-solu tion-focused-approach

[27] Wilson, K. (2019) The Rage Less Travelled. Open Wound Publishers, Jerusalem.

[28] Drury, N. (2014) A Taste of Wittgenstein for SFBT. 1: The Tractatus. Journal of Solution-Focused Brief Therapy, 1, 11-29.

[29] Wittgenstein, L. (2005) The Big Typescript: TS 213. Wiley-Blackwell, New York. https://doi.org/10.1002/9780470752906

[30] Wittgenstein, L. (1961) Tractatus Logico-Philosophicus, §5.1361. Routledge, New York.

[31] George, E., Ratner, H. and Iveson, C. (1999) Problem to Solution: Brief Psychotherapy with Individuals and Families. BT Press, London.

[32] Bouveresse, J. (1995) Wittgenstein Reads Freud: The Myth of the Unconscious (Cosman, C., Trans.). Princeton University Press, Princeton.

[33] Iveson, C. and McKergow, M. (2016) Brief Therapy Development: Focused Description Development. Journal of Solution-Focused Brief Therapy, 2, 1-17.

[34] Wittgenstein, L. (1958) Philosophical Investigations (Anscombe, G.E.M., Trans.). Macmillan, New York.

[35] Simon, J. (2018) SOL Listserv Posting. http://SFT-L@listserv.icors.org

[36] Gingerich, W.J., Kim, J., Stams, G.J.J., et al. (2011) Current Evidence Base for Solution Focused Therapy. In: Franklin, C., Trepper, T.S. and Gingerich, W.J., et al., Eds., Solution-Focused Brief Therapy: A Handbook of Evidence-Based Practice, Oxford University Press, New York. https://doi.org/10.1093/acprof:oso/9780195385724.003.0043

[37] Wittgenstein, L. (1969) On Certainty, \$253. Harper, New York. 